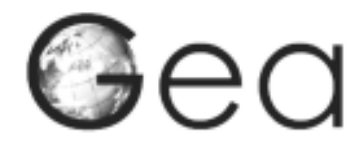

JURNAL PENDIDIKAN GEOGRAFI

\title{
PENERAPAN PRINSIP GEOGRAFI UNTUK KONSERVASI SUMBER DAYA ALAM DI WILAYAH BOGOR BARAT KABUPATEN BOGOR JAWA BARAT
}

\author{
Ana Widiyati \\ SMA Negeri 1 Dramaga Kabupaten Bogor \\ email: ana_widiya@yahoo.co.id
}

\begin{abstract}
ABSTRAK
Geografi sebagai salah satu ilmu yang menelaah tentang fenomena di permukaan bumi serta timbal balik antara manusia dan lingkungan diharapkan mampu memberikan solusi pemecahan berbagai masalah di suatu wilayah. Salah satunya memberikan solusi dalam upaya konservasi sumber daya alam melalui penerapan prinsip geografi.Provinsi Jawa Barat dikenal memiliki sumber daya alam yang melimpah di antaranya termasuk Kabupaten Bogor. Wilayah Bogor Barat merupakan wilayah di Kabupaten Bogor yang kaya akan sumber daya alam. Penulisan ini bertujuan menerapkan prinsip geografi dalam upaya konservasi sumber daya alam di wilayah Bogor Barat Kabupaten Bogor Jawa Barat. Melalui tulisan ini diharapkan dapat memberikan wawasan serta solusi kepada masyarakat dan pemerintah dalam upaya konservasi sumber daya alam di Wilayah Bogor Barat, Kabupaten Bogor, Jawa Barat. Dari hasil analisis disimpulkan bahwa penerapan prinsip geografi dalam upaya konservasi sumber daya alam di wilayah Bogor Barat Kabupaten Bogor Jawa Barat dilakukan dengan cara mengidentifikasi dan inventarisasi sumber daya alam di setiap wilayah dari wilayah yang terkecil kemudian hasil dari identifikasi dan inventarisasi sumber daya alam di tiap daerah diuraikan dan dijelaskan melalui tabel, peta, dan grafik. Berikutnya menjelaskan keterkaitan antara faktor-faktor yang memengaruhi sumber daya alam di suatu wilayah. Penulis memberikan saran agar dalam upaya konservasi sumber daya alam pemerintah melakukan sosialisasi kepada masyarakat sehingga timbul kesadaran dan tanggung jawan untuk menjaga lingkungan. Selain itu, diperlukan kebijakan yang tepat oleh pemerintah dalam upaya konservasi sumber daya alam di wilayah Bogor Barat Kabupaten Bogor.
\end{abstract}

Kata kunci : Prinsip geografi, konservasi, sumber daya alam.

\section{PENDAHULUAN}

\section{Latar Belakang Masalah}

Tidak semua wilayah di muka bumi ini memiliki beragam sumber daya alam, bersyukur Indonesia merupakan salah satu negara yang memiliki keberagaman jenis sumber daya alam yang melimpah. Sumber daya alam sangat penting bagi keperluan hidup, seperti tumbuhan, hewan, air, mineral, dan bahan-bahan galian lainnya. Sumber daya alam yang melimpah di Indonesia saat ini menjadi perhatian utama untuk dijaga kelestariannya. Indonesia memiliki wilayah hutan tropis terluas ketiga di dunia dengan cadangan minyak, gas alam, emas, tembaga dan mineral lainnya. Terumbu Karang dan kehidupan laut memperkaya ribuan pulaunya. Lebih dari itu, Indonesia memiliki tanah dan dan area lautan yang luas, dan kaya dengan berjenis- 
jenis ekologi. Menempati hampir 1,3\% dari wilayah bumi, mempunyai kira-kira $10 \%$ jenis tanaman dan bunga yang ada di dunia, $12 \%$ jenis binatang menyusui, $17 \%$ jenis burung, $25 \%$ jenis ikan (World Bank, 1994). Melimpahnya sumber daya alam hampir merata di seluruh wilayah Indonesia beserta pulau-pulaunya. Antara wilayah satu dan wilayah lainnya di Indonesia memiliki ciri khas keberagaman sumber daya alam yang berbeda.

Jawa Barat merupakan salah satu provinsi di Indonesia yang kaya akan sumber daya alam. Provinsi ini memiliki lahan persawahan yang menghasilkan tanaman palawija, hortikultura, sayuran, buah-buahan dan tanaman obat. Selain itu 20,62 \% wilayah berupa hutan yang terdiri atas hutan lindung, hutan konservasi dan hutan produksi. Jawa Barat juga menghasilkan hasil hutan non kayu cukup potensial dikembangkan sebagai aneka usaha kehutanan, antara lain sutera alat jamur, pinus, gerah damar, kayu putih, rotan, bambu, dan sarang burung walet. Budidaya perikanan darat juga sangat berkembang di Provinsi Jawa Barat.

Agar sumber daya alam yang melimpah di Jawa Barat dapat dimanfaatkan dan dijaga kelestariannya maka tiap-tiap wilayah kota atau kabupaten di Jawa Barat harus berperan dalam upaya konservasi sumber daya alam. Salah satu kabupaten di Jawa Barat yang saat ini sedang giat dalam upaya konservasi sumber daya alam adalah kabupaten Bogor. Wilayah Kabupaten merupakan wilayah yang sangat luas yaitu 298.838,304 hektar yang terbagi ke dalam 40 kecamatan. Wilayah yang sangat luas tersebut menimbulkan wacana pemekaran Kabupaten Bogor menjadi Kabupaten Bogor Barat.

Bogor Barat adalah daerah yang terletak disebelah barat Kabupaten dengan luas 1,2 ribu hektar terdiri atas 14 kecamatan, 200 desa dan berpenduduk sekita 1,4 juta jiwa. Bogor barat sangat berpotensi untuk maju dan berkembang, karena memiliki sumber daya alam dan juga sumber daya manusia yang sangat mendukung. Bogor Barat memiliki potensi sumbe rdaya alam hayati, sumber daya alam mineral, pariwisata, bahkan pusat pengembangan ilmu pengetahuan.

Potensi sumber daya alam yang melimpah di wilayah Bogor Barat seringkali kurang diimbangi dengan upaya pelestarian atau konservasi yang tepat. Masyarakat seringkali kurang memahami arti penting sumber daya alam bagi kelangsungan kehidupan di masa depan. Konservasi sumber daya alam selain dilakukan oleh instansi pemerintah juga diperlukan peran serta masyarakat. Sehingga sudah saatnya berbagai alternatif dalam upaya konservasi sumber daya alam perlu dilakukan.

\section{Perumusan Masalah}

Bagaimana penerapan prinsip geografi untuk konservasi sumber daya alam di Wilayah Bogor Barat Kabupaten Bogor Jawa Barat?

\section{Tujuan dan Manfaat Penulisan}

Tujuan yang hendak dicapai dari penelitian ini adalah 1) ingin mengetahui penerapan prinsip geografi untuk konservasi sumber daya alam di Wilayah Bogor Barat, Kabupaten Bogor, Jawa Barat; 2) Ingin mengemukakan alternatif konservasi sumber daya alam di Wilayah Bogor Barat, Kabupaten Bogor, Jawa Barat.

Adapun manfaat penelitiannya adalah 1) Manfaat bagi masyarakat yaitu dapat memberikan wawasan agar dapat berpartisipasi aktif dalam upaya konservasi sumber daya alam di Wilayah Bogor Barat, Kabupaten Bogor, Jawa Barat; 2) Manfaat bagi pemerintah yaitu sebagai solusi alternatif yang dapat dijadikan pertimbangan dalam upaya konservasi sumber daya alam di Wilayah Bogor Barat, Kabupaten Bogor, Jawa Barat 


\section{HASIL DAN PEMBAHASAN}

\section{Kondisi Geografis Wilayah Bogor Barat}

Wilayah Bogor Barat merupakan bagian dari wilayah kabupaten Bogor Jawa Barat yang terdiri atas 14 kecamatan yaitu: Nanggung, Leuwiliang, Leuwisadeng, Pamijahan, Cibungbulang, Ciampea, Tenjolaya, Tenjo, Rumpin, Jasinga, Parung Panjang, Sukajaya, Cigudeg, dan Dramaga. Tipe morfologi wilayah ini bervariasi, dari dataran yang relatif rendah di bagian utara hingga dataran tinggi di bagian selatan, yaitu 30 - 2500 meter diatas permukaan laut (dpl).

Hampir sama dengan wilayah Kabupaten Bogor, jenis batuan penyusunnya didominasi oleh hasil letusan gunung, yang terdiri dari andesit, tufa dan basalt. Curah hujan rata-ratanya berkisar antara 3.000 sampai $5.000 \mathrm{~mm} /$ tahun sedangkan temperatur rata-rata berada pada suhu $26^{\circ}$ C. Batas administrasi wilayah Bogor Barat adalah :

$\begin{array}{lll}\text { Sebelah Utara } & : & \text { Kabupaten Tangerang } \\ \text { Sebelah Timur } & : & \begin{array}{l}\text { Kecamatan Gunung Sindur, Ciseeng, } \\ \text { Rancabungur, Ciomas, Tamansari, Kota Bogor }\end{array} \\ \text { Sebelah Barat } & : & \text { Kabupaten Lebak Banten } \\ \text { Sebelah Selatan } & : & \text { Kabupaten Sukabumi }\end{array}$

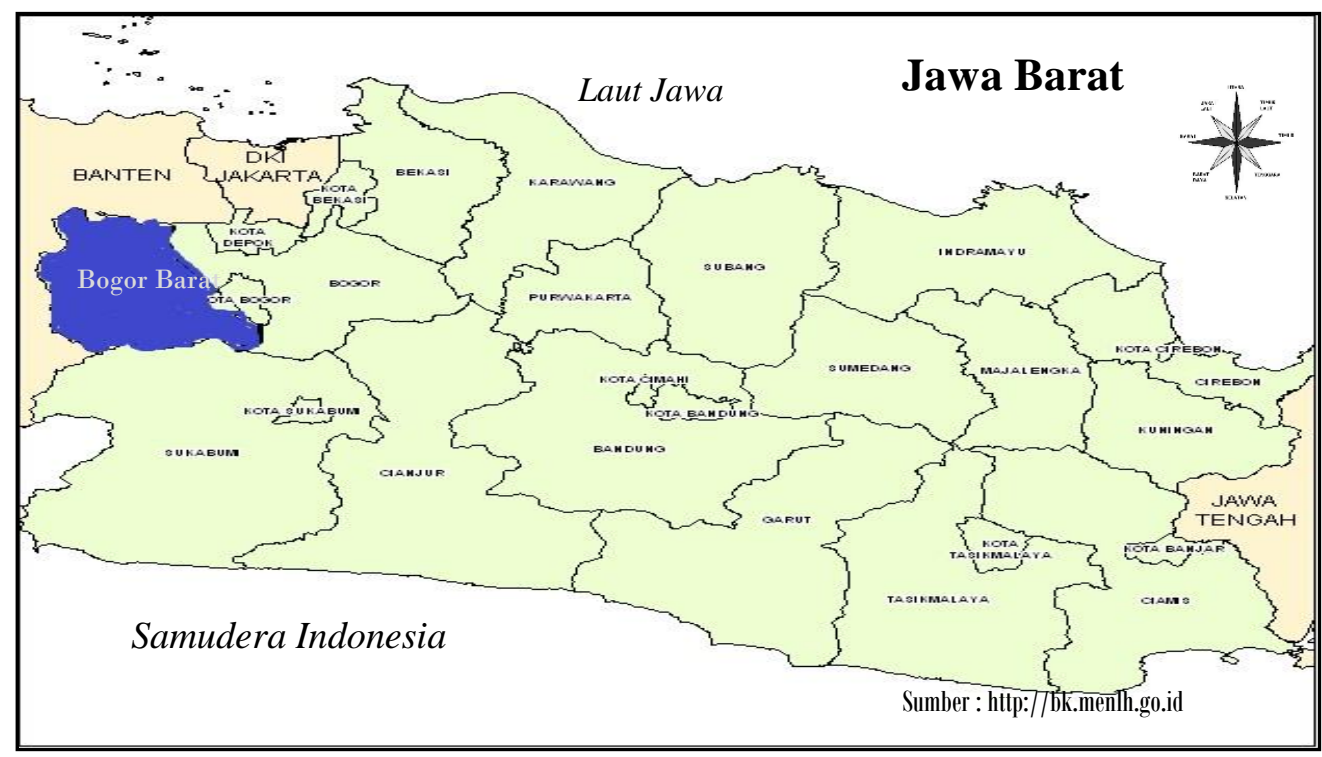

Gambar 1. Lokasi Wilayah Bogor Barat

\section{Sumber Daya Alam di Wilayah Bogor Barat}

Berbagai jenis sumber daya alam yang tersebar di wilayah Bogor adalah sebagai berikut:

1) Sumber daya alam yang dapat diperbarui terdiri dari: hutan yang terdiri atas hutan lindung dan hutan produksi; sumberdaya air berupa air sungai untuk keperluan hidup sehari-hari maupun untuk keperluan pertanian dan perikanan; flora dan fauna yang dikelola dalam suatu kawasan konservasi cagar alam dan taman nasional; pertanian yang meliputi padi, palawija, sayuran dan buah-buahan; perkebunan yang meliputi perkebunan teh dan perkebunan karet; peternakan yang dibagi menjadi peternakan domba, kambing, sapi potong, sapi perah, dan peternakan unggas; perikanan terdiri atas adalah perikanan air tawar 
misalnya ikan emas, gurame, ikan bawal dan ikan hias; dan plasma Nuftah atau sumberdaya genetik. Plasma nutfah adalah substansi sebagai sumber sifat keturunan yang terdapat di dalam setiap kelompok organisme yang dapat dimanfaatkan dan dikembangkan atau dirakit agar tercipta suatu jenis unggul atau jenis baru.

2) Sumber daya alam yang tidak dapat diperbarui, seperti: bahan galian strategis (golongan A) berupa batuan timah hitam; bahan galian vital (golongan B) terdiri dari emas, perak, tembaga dan seng; dan bahan galian golongan $\mathrm{C}$ terdiri dari batu kapur, batu kali, kerikil dan pasir.

\section{Penerapan Prinsip Geografi dalam Upaya Konservasi Sumber Daya Alam di Wilayah Bogor Barat}

Sumber daya alam di wilayah Bogor perlu dilestarikan melalui upaya konservasi. Konservasi sumber daya alam dapat diartikan sebagai pengelolaan sumber daya alam yang dapat menjamin pemanfaatannya secara bijaksana baik kualitas maupun keanekaragamannya secara berkesinambungan. Salah satu upaya konservasi sumber daya alam di Bogor dapat dilakukan dengan cara menerapkan prinsip-prinsip geografi, seperti pada gambar skema berikut.

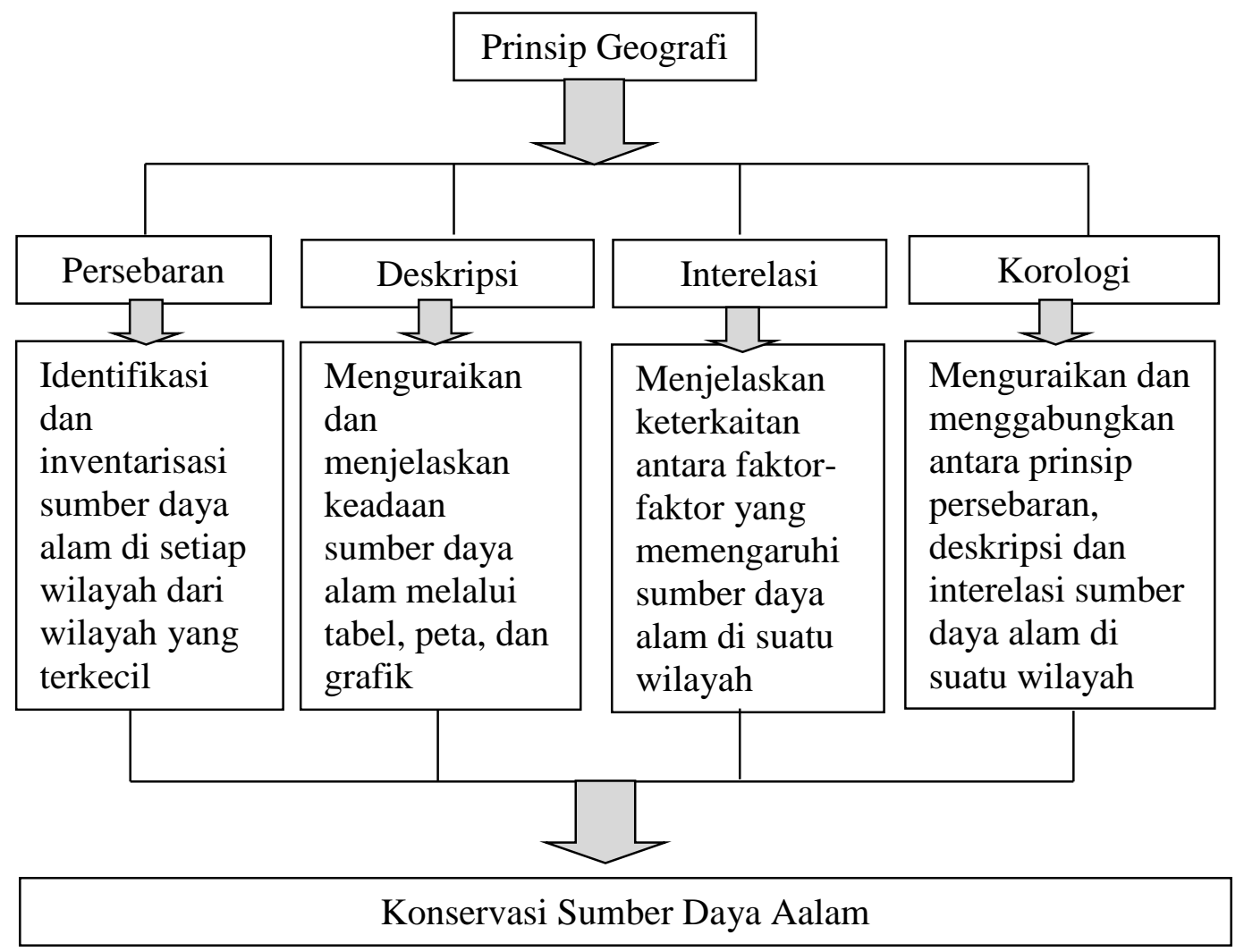

Gambar 2. Skema Penerapan Prinsip Geografi

Data dan fakta menunjukkan bahwa sumber daya alam di wilayah Bogor Barat tersebar tidak merata. Sumber daya alam yang terdapat di suatu daerah berbeda dengan daerah lain tergantung pada faktor yang memengaruhinya. Kondisi geografis di wilayah Bogor Barat dengan curah hujan yang tinggi menyebabkan sumber daya alam yang terdapat di wilayah Bogor Barat sebagian besar adalah sumber daya alam pertanian, perkebunan, peternakan dan 
perikanan. Namun ada beberapa kecamatan yang memiliki sumber daya alam tambang karena dipengaruhi oleh kondisi geologi wilayah tersebut.

Konservasi sumber daya alam di wilayah Bogor Barat dengan menerapkan prinsip persebaran dilakukan dengan cara identifikasi dan inventarisasi sumber daya alam dimulai dari wilayah yang relatif kecil misalnya wilayah kecamatan. Melalui inventarisasi dapat diketahui kekurangan dan kelebihan sumberdaya alam pada masing-masing wilayah tersebut. Hasil inventarisasi dari masing-masing wilayah kemudian disosialisasikan kepada masyarakat sehingga masyarakat memiliki rasa tanggung jawab untuk ikut menjaga dan melestarikan kekayaan sumber daya alam yang mereka miliki.

Persebaran sumber daya alam yang tidak merata di wilayah Bogor dapat dijelaskan lebih lanjut melalui prinsip deskripsi. Prinsip deskripsi merupakan gambaran atau penjelasan dari fenomena yang terjadi di permukaan bumi dengan menggunakan tabel, gambar, peta, grafik, diagram, bagan dan lain-lain. Berikut ini adalah tabel konservasi sumber daya alam di tiap-tiap kecamatan di wilayah Bogor Barat :

Tabel 1. Konservasi Sumber Daya Alam di wilayah Bogor Barat

\begin{tabular}{cll}
\hline No. & Macam konservasi SDA & \multicolumn{1}{c}{ Kecamatan } \\
\hline 1 & Hutan lindung & Nanggung, Pamijahan, Jasinga, Sukajaya, Cigudeg \\
\hline 2 & Daerah resapan air & Nanggung, Leuwiliang, Leuwisadeng, Pamijahan, Tenjolaya \\
\hline 3 & Cagar alam & Rumpin \\
\hline 4 & Taman Nasional & Leuwiliang, Pamijahan, Tenjolaya, Sukajaya \\
\hline 5 & Konservasi geologi & Ciampea, Cigudeg \\
\hline 6 & Hutan Produksi & $\begin{array}{l}\text { Nanggung, Leuwiliang, Leuwisadeng, Cibungbulang, Ciampea, } \\
\text { Tenjo, Rumpin, Jasinga, Parung Panjang, Sukajaya, Cigudeg }\end{array}$ \\
\hline 7 & Pertanian & $\begin{array}{l}\text { Nanggung, Leuwiliang, Leuwisadeng, Pamijahan, Cibungbulang, } \\
\text { Ciampea, Tenjo, Rumpin, Jasinga, Parung Panjang, Sukajaya, }\end{array}$ \\
\hline 8 & Perkebunan & Cigudeg, Dramaga \\
\hline 10 & Peternakan & Nanggung, Rumpin, Jasinga, Sukajaya, Cigudeg \\
\hline 11 & Bahan galian & Nanggung, Leuwiliang, Pamijahan, Cibungbulang, Ciampea, Tenjo, \\
& & Jasinga, Parung Panjang, Sukajaya, Cigudeg \\
\hline 12 & Plasma Nuftah & Leuwiliang, Pamijahan, Cibungbulang, Ciampea, Dramaga \\
\hline & & Nanggung, Leuwiliang, Leuwisadeng, Tenjo, Rumpin, Jasinga, \\
\end{tabular}

Prinsip deskripsi digunakan dalam analisis konservasi sumber daya alam di wilayah Bogor Barat yang berarti menguraikan secara jelas tentang konservasi sumber daya alam tersebut, disertai dengan penjelasan. Berikut ini salah satu penerapan prinsip deskripsi dalam menganalisi sumber daya alam perikanan di wilayah Bogor Barat dapat dilihat pada gambar 3 .

Jika dianalisis lebih lanjut perbedaan sumber daya alam antara satu daerah dengan daerah lain dipengaruhi oleh berbagai faktor. Keterkaitan antara satu faktor dengan faktor lain dalam memandang suatu fenomena dalam geografi merupakan prinsip interelasi. Prinsip interelasi menjelaskan keterkaitan antara faktor-faktor yang memengaruhi fenomena dalam ruang tertentu, misalnya antara faktor fisik dengan faktor fisik, maupun antara faktor fisik dan faktor non fisik. Prinsip interelasi dalam upaya konservasi sumber daya alam di wilayah Bogor Barat dapat dijelaskan sebagai berikut :

1) Kondisi geografis Kecamatan Jasinga dengan curah hujan tinggi yaitu rata-rata 3000 $\mathrm{mm} /$ tahun, keadaan topografi 175 di atas permukaan laut menyebabkan kawasan ini cocok menjadi kawasan hutan lindung yang terdapat berbagai keanekaragaman hayati baik flora maupun fauna. 
2) Kecamatan Leuwiliang dan Pamijahan dengan ketinggian 800-1000 mdpl, curah hujan ratarata $5238 \mathrm{~mm} /$ tahun, suhu berkisar antara $19-30^{\circ} \mathrm{C}$ serta kelembaban udara $38-80 \%$ menyebabkan di wilayah ini terdapat sumber daya alam berupa perkebunan teh. Sumberdaya alam ini menjadi mata pencaharian bagi penduduk di sekitar perkebunan teh tersebut.

3) Kawasan yang kaya akan tambang emas di Kecamatan Nanggung menyebabkan banyaknya masyarakat yang menjadi penambang liar. Akibat dari kagiatan tersebut sering terjadi longsoran tanah yang seringkali memakan korban jiwa.

4) Banyaknya aliran sungai di wilayah Leuwiliang, Pamijahan, Cibungbulang, Ciampea, dan Dramaga menyebabkan wilayah ini menjadi pusat kegiatan perikanan air tawar yang memasok kebutuhan ikan di wilayah lain.

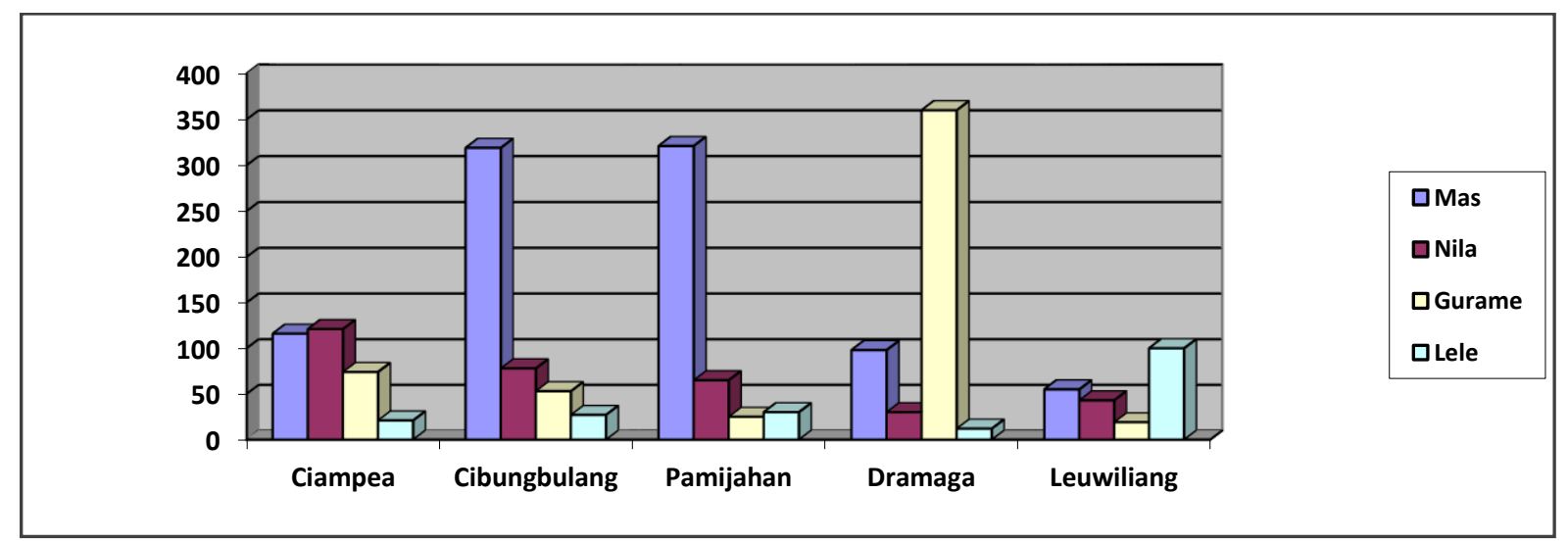

Gambar 3. Grafik Produksi Perikanan Air Tawar (kilogram) di lima kecamatan di wilayah Bogor Barat

Setelah menerapkan prinsip persebaran, deskripsi dan interelasi, maka konservasi sumberdaya alam akan lebih jelas jika menerapkan prinsip korologi. Prinsip korologi dalam konservasi sumberdaya alam diterapkan dengan cara menguraikan dan menggabungkan antara prinsip persebaran, deskripsi dan interelasi dalam ruang tertentu di muka bumi. Melalui prinsip korologi ini, konservasi sumber daya alam dapat digambarkan dengan jelas, dikaji berbagai gejala dan permasalahan yang mungkin akan timbul.

Penerapan prinsip korologi dalam upaya konservasi sumberdaya alam dapat digambarkan pada gambar 4 .

\section{SIMPULAN}

Kekayaan sumber daya alam di Kabupaten Bogor terutama wilayah Bogor Barat diperlukan penanganan yang tepat. Salah satu ilmu pengetahuan yang dapat memberikan sumbangan terhadap upaya konservasi sumber daya alam adalah ilmu geografi dengan menerapkan prinsip geografi. Prinsip geografi yang terdiri atas prinsip persebaran, prinsip deskripsi, prinsip interelasi dan prinsip korologi dapat diterapkan dalam upaya konservasi sumber daya alam di wilayah Bogor Barat. Penerapannya dengan cara mengidentifikasi dan inventarisasi sumber daya alam di setiap wilayah dari wilayah yang terkecil. Hasil dari identifikasi dan inventarisasi sumber daya alam di tiap daerah tersebut diuraikan dan dijelaskan 


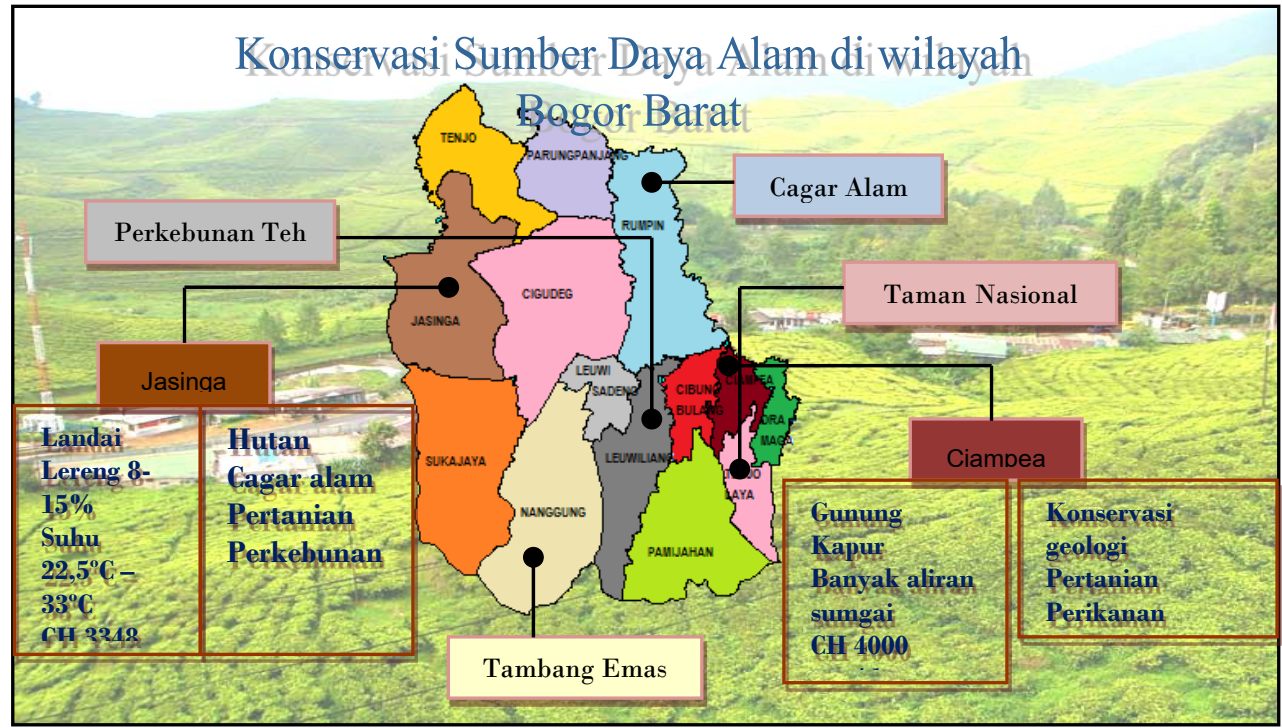

Gambar 4. Prinsip Korologi Konservasi Sumber daya Alam di wilayah Bogor Barat

melalui tabel, peta, dan grafik. Berikutnya menjelaskan keterkaitan antara faktor-faktor yang memengaruhi sumber daya alam di suatu wilayah.

Prinsip korologi merupakan gambaran jelas mengenai fenomena keruangan di muka bumi. Penerapan prinsip korologi dalam upaya konservasi sumber daya alam dilakukan dengan menguraikan dan menggabungkan antara prinsip persebaran, deskripsi dan interelasi sumber daya alam di suatu wilayah melalui deskripsi yang lengkap dan jelas.

Adapun saran yang diajukan adalah 1) Upaya konservasi sumber daya alam di wilayah Bogor Barat diperlukan kebijakan pemerintah yang tepat salah satunya dengan menerapkan ilmu pengetahuan termasuk prinsip-prinsip geografi; 2) Penanganan konservasi sumber daya alam di wilayah Bogor Barat juga diperlukan peran aktif masyarakat, oleh karena itu perlu sosialisasi upaya konservasi sumber daya alam kepada masyarakat.

\section{DAFTAR PUSTAKA}

Badan Perencanaan dan Pembangunan Daerah.(2010). http://bappeda.bogorkab.go.id/. [10 Desember 2010].

Dinas Kehutanan Provinsi Jawa Barat. (2010). http://bbksda-jabar.dephut.go.id. [10 Desember 2010].

Dinas Peternakan dan Perikanan. (2009). http://disnakan.bogorkab.go.id. [12 Desember 2010].

Dinas Tata Ruang dan Lingkungan Hidup. (2010). http://dtrlh.bogorkab.go.id. [11 Desember 2010].

Nursid, S. (1988). Studi Geografi Suatu Pendekatan dan Analisa Keruangan. Bandung : Penerbit PT. Alumni.

Peraturan Daerah Kabupaten Bogor. No. 19 tahun 2008. http://jdih.bogorkab.go.id. [10 Desember 2010].

Sistem Informasi Manajeman Geografi Daerah Kabupaten Bogor http://simgd.bogorkab.go.id . [13 Desember 2010].

Supardi, Imam. (2003). Lingkungan Hidup dan Pelestariannya. Bandung: Penerbit PT. Alumni. 
Waluya, Bagja. (2009). Memahami Geografi untuk kelas X SMA/MA. Pusat Perbukuan Departemen Pendidikan Nasional. Jakarta.

Zoer'aini, D. I. (2010). Prinsip-prinsip Ekologi Ekosistem Lingkungan dan Pelestariannya. Jakarta: Bumi Aksara. 